\title{
Commentary: Faster recovery after complex neonatal cardiac surgery
}

\author{
Shu-Chien Huang, MD, PhD, and Chi-Hsiang Huang, MD
}

\footnotetext{
From the Department of Surgery and Anesthesiology, National Taiwan University Hospital, National Taiwan University College of Medicine, Taipei, Taiwan.

Disclosures: Authors have nothing to disclose with regard to commercial support.

Received for publication Nov 13, 2018; accepted for publication Nov 13, 2018; available ahead of print Dec 20 , 2018.

Address for reprints: Shu-Chien Huang, MD, PhD, Department of Surgery, National Taiwan University Hospital,

7 Chung-Shan South Rd, Taipei 100, Taiwan (E-mail: cvshuang@ gmail.com).

J Thorac Cardiovasc Surg 2019;157:1601-2

$0022-5223 / \$ 36.00$

Copyright (c) 2018 by The American Association for Thoracic Surgery

https://doi.org/10.1016/j.jtcvs.2018.11.050
}

Early extubation in congenital cardiac surgery reduces the complications associated with prolonged intubation, avoiding the consequences of sedation and the effects of positive-pressure ventilation. ${ }^{1}$ Early extubation has a greater success rate in children with greater body weights and those undergoing shorter surgical procedures. ${ }^{2}$ Delayed extubation is considered an indicator of poor outcomes in most quality control programs. In the Society of Thoracic Surgeons database, early extubation after Fontan operation or repairing tetralogy of Fallot is mostly discussed.

In this issue of the Journal, Varghese and colleagues ${ }^{4}$ are the first to publish outcomes of immediate extubation $(\mathrm{IE} ; \mathrm{n}=5)$ in the operating room $(\mathrm{OR})$ after Norwood stage 1 palliation (S1P) with satisfactory clinical outcomes.

Few studies have found a difference between IE in the OR and early extubation in the intensive care unit. We posit that these 2 treatments should have the same clinical results. Furthermore, extubation in the OR carries an additional risk of airway uncertainty during patient transportation. The benefits of IE after Norwood S1P are hard to determine from the work of Varghese and colleagues because of the small patient groups in their study. However, successful IE after Norwood S1P in this case series is a benchmark of success in the field of complex neonatal cardiac surgery, especially because Norwood S1P is the greatest-risk category in the congenital heart surgery database.

The prerequisite of successful IE is perfect anatomical repair and minimal intraoperative insult. Varghese and colleagues chose to use a right ventricle-to-pulmonary artery shunt rather than a Blalock-Taussig shunt, which might have more stable hemodynamic status immediately after surgery. ${ }^{5}$ In addition, they chose a dual arterial cannulation technique to achieve continuous mild hypothermia bypass. Avoiding deep hypothermic circulatory arrest may decrease hemodynamic instability and end-organ

\section{References}

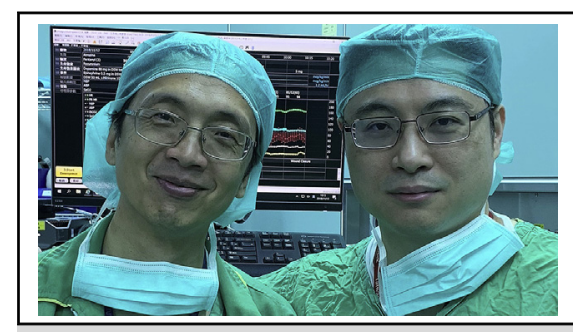

Drs Chi-Hsiang Huang (left) and Shu-Chien Huang (right)

Central Message

Early extubation after complex neonatal surgery should be the result of excellent surgery and comprehensive perioperative care.

See Article page 1591.

ischemia-reperfusion injury; the benefits of the warm bypass strategy in Norwood S1P warrant further study using a larger patient series.

The anesthetic management included preoperative adjustment of a patient's medication and volume status, judicious use of anesthetic medications intraoperatively, hemodynamic and hemostatic management, normothermia, and well-planned postoperative analgesia and sedation. These factors are crucial for achieving IE in patients after congenital heart surgery.

Despite the success of early extubation, the length of stay was still jeopardized by arrhythmia, low-output syndrome, chylothorax, vocal cord palsy, and feeding problems. Furthermore, extubation failure is associated with increased mortality in the literature. ${ }^{6}$

We deem early extubation to be a surrogate for fast physiological recovery. Fast recovery, including removal of the endotracheal tube, sedation, and inotropic agents, requires a perfect anatomical repair, minimal physiological disarrangement, and optimal anesthetic management to simplify postoperative care and facilitate enhanced recovery. Enhanced recovery for patients and the improved long-term outcome, not solely faster extubation, should be the primary goal in congenital cardiac surgery.

1. Winch PD, Staudt AM, Sebastian R, Corridore M, Tumin D, Simsic J, et al Learning from experience: improving early tracheal extubation success after congenital cardiac surgery. Pediatr Crit Care Med. 2016;17:630-7. 
2. Harris KC, Holowachuk S, Pitfield S, Sanatani S, Froese N, Potts JE, et al. Should early extubation be the goal for children after congenital cardiac surgery? J Thorac Cardiovasc Surg. 2014; 148:2642-7.

3. Jacobs ML, Jacobs JP, Hill KD, Hornik C, O'Brien SM, Pasquali SK, et al. The Society of Thoracic Surgeons Congenital Heart Surgery Database: 2017 update on research. Ann Thorac Surg. 2017;104:731-41.

4. Varghese J, Hammel JM, Ibrahimiye A, Siecke R, Moukagnae K, Kutty S. Outcomes related to immediate extubation after stage 1 Norwood palliation for hypoplastic left heart syndrome. J Thorac Cardiovasc Surg. 2019;157: 1591-8.

5. Barron DJ. The Norwood procedure: in favor of the RV-PA conduit. Semin Thorac Cardiovasc Surg Pediatr Card Surg Annu. 2013;16:52-8.

6. Scodellaro T, McKenzie JM, d'Udekem Y, Butt W, Namachivayam SP. Extubation failure is associated with increased mortality following first stage single ventricle reconstruction operation. Pediatr Crit Care Med. 2017;18: 1136-44. 